\title{
Numerical comparison for thermo-hydraulic performance of pin fin heat sink with micro channel pin fin heat sink
}

\author{
V SARAVANAN $^{1,2, *}$ and C K UMESH ${ }^{3}$ \\ ${ }^{1}$ Department of Mechanical Engineering, B.N.M. Institute of Technology, Bangalore, India \\ ${ }^{2}$ UVCE, Bangalore, India \\ ${ }^{3}$ Department of Mechanical Engineering, University Visvesvaraya College of Engineering, Bangalore, India \\ e-mail: saravanan.venkatesh@gmail.com; umeshuvce@yahoo.co.in
}

MS received 17 August 2017; revised 10 March 2018; accepted 22 March 2018; published online 18 June 2018

\begin{abstract}
Cooling of miniature size electronic components has become a challenge for designer in the development of integrated circuits. Micro pin fin heat sink and Micro channel pin fin heat sink are thermal management techniques for effective cooling. The paper presents comparison of fluid flow and heat transfer characteristics for micro pin fin heat sink and micro channel pin fin heat sink with unfinned micro channel heat sink. A three-dimensional heat sink with water as coolant subjected to constant heat flux $10 \mathrm{~W} / \mathrm{cm}^{2}$, for Reynolds number ranging between 100 and 900 was considered for the study. Extended surfaces of different shapes namely, square and circular with staggered arrangement was considered for both micro pin fin heat sink and micro channel pin fin heat sink. Two non-dimensional parameters namely Nusselt number and thermal performance index were employed to access the performance of heat sink. Results indicate that the microchannel pin fin heat sink has highest nusselt number and friction factor over the whole Reynolds number range. Results also revealed that formation of secondary vortices enhances heat transfer in micro channel heat sink with square pin fin compared to micro channel heat sink with circular pin fin. However, pin fin heat sink has better thermal performance index compared to Micro channel pin fin heat sink and is more preferable when heat dissipation is compared with pressure drop penalty. The Governing equations for fluid and solid domain were solved using FLUENT to study flow and heat transfer characteristics.
\end{abstract}

Keywords. Micro channel; micro pin fin; heat sink; square pin fin; circular pin fin.

\section{Introduction}

With rapid development in power electronics, thermal management of small-sized electronic components has become a highly challenging problem for designer. The components are highly delicate and the critical factor which determines the life span is the operating temperature. Care has to be taken to maintain the maximum surface temperature beyond safe limit, failing would hinder long term operation of electronic devices. Presently, the researcher has proposed a solution to dissipate larger heat flux by employing micro pin fin heat sink and micro channel heat sink for efficient cooling. These heat sink are fabricated using micro machining techniques and are deemed to be advantageous where parameters like thermal resistance and heat transfer coefficient are concerned. They exhibit low thermal resistance, high heat transfer coefficient, greater heat transfer surface area and required minimum inventory which are favorable for heat dissipation. Moreover, these heat sinks are slightly modified by having either staggered

*For correspondence or inline pin fin arrangements which proved to be more effective. The heat sink had the potential to dissipate larger magnitude of heat through smaller areas with an appreciable increase in the pressure drop.

The concept of micro channel was first proposed by Tuckerman and Pease [1], Shafeie et al [2] numerically studied the performance of heat sink with staggered and oblique arrangement and observed that oblique pin fin performs better compared to staggered for a given pumping power. Hydrodynamic and heat transfer characteristics have been explored numerically for heat sink with pin fin structures by Turker Izci et al [3], Hasan et al [4] numerically compared hydrodynamic and heat transfer characteristics of micro pin fin heat sink of different shapes using water and Nano fluids. Sohail et al [5] proposed pin fin array of various shapes to reduce maximum surface temperature. Later Abdoli et al [6] numerically investigated the influence of different pin fin shapes for cooling of electronic chips and reported pin fin with convex and hydrofoil shape performed better compared to circular cross section. Carlos et al [7] proposed variable fin density heat sink of different shapes namely circle, square, elliptical and flat 
plate to maintain uniform temperature of integrated chips. Flat shaped pin fins were observed to be superior compared to other shapes. Liu et al [8] experimentally proved that pin fin shape has significant effect on heat transfer at larger Reynolds number. Yavo poles et al [9] experimentally proved that the thermal resistance can be greatly reduced by employing pin fin heat sink. Zhao et al [10] experimentally showed that elliptical pin fin has better stream line with low thermal resistance and triangular pin fin has larger flow resistance compared to other shapes. John et al [11] proposed a non-dimensional zed parameter to access the performance of pin fin heat sink and proved circular fins are effective for Reynolds number smaller than 300 and square fins are better for Reynolds number greater than 300. Kosar and Peles et al [12] compared the performances of micro pin fin heat sink of different shapes namely circular, rectangular, hydrofoil, and cone-shaped. They concluded that at high Reynolds number pin fin with denser configuration has better performance, whereas sparsely configuration is better at low Reynolds number. Bayram Sahin et al [13] experimentally proved heat sink with square pin fin results in heat transfer enhancement and developed correlation for enhancement efficiency.

Judy et al [14] investigated pressure drop through micro channels with different cross sections. Lee et al [15] experimentally investigated heat transfer in rectangular micro channels, effect of surface roughness on micro channel heat sink was studied by Giulio et al [16]. Welin $\mathrm{Qu}$ et al [17, 18] conducted experiments through micro channel heat sink and compared the experimental results using three-dimensional conjugate model numerically, later viscosity model and roughness viscosity model were proposed to interpret experimental data. Dorin lelea et al [19] experimentally studied the performance of micro tubes using distilled water. Reiyu cheien et al [20] numerically investigated micro channel heat sink with different inlet and outlet arrangements and concluded heat sink performs better when coolant is collected vertical. Harms et al [21] reported that micro channel heat sink with smaller width and larger depth performs better. Marino et al [22] reported experimental results for heat transfer in micro channel heat sink. Peng et al [23] experimentally studied the influence of geometry on the performance of micro channel and concluded heat transfer under laminar regime is highly dependent on aspect ratio. Wu et al [24] experimentally predicted transition zone for flow inside microchannel and showed hydrodynamic and heat transfer characteristics increased with surface roughness. Zhang et al [25] proposed parallel and counter flow micro channel heat sink with bifurcations to minimize micro channel heat sink temperature. Results reveal that counter flow heat sink performs better than parallel flow and by employing bifurcation the thermal performance can be greatly enhanced. Yadav et al [26] studied the performance of micro channel with extended surface at different position.

As discussed above, studies available in open literature are mostly focussed on heat sink with different pin fin shapes and rectangular micro channel heat sink. None of the studies reports the combined effect of pin fin heat sink and micro channel heat sink. The prime focus of the present

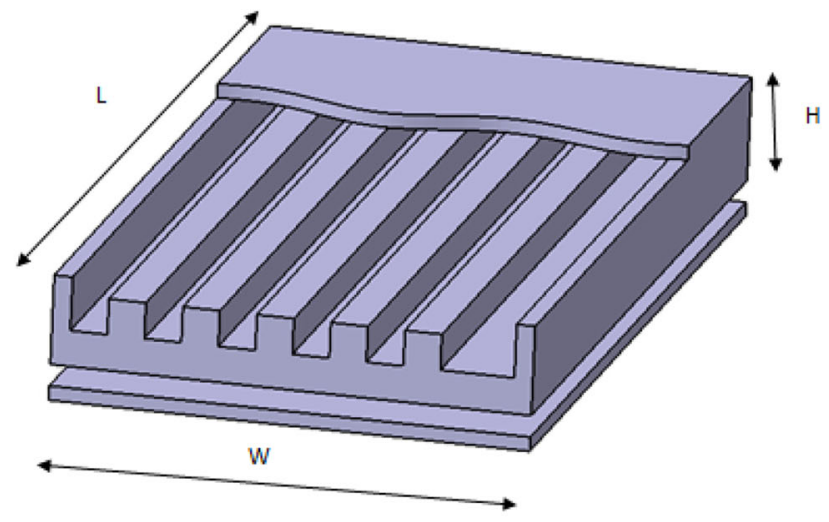

(a)

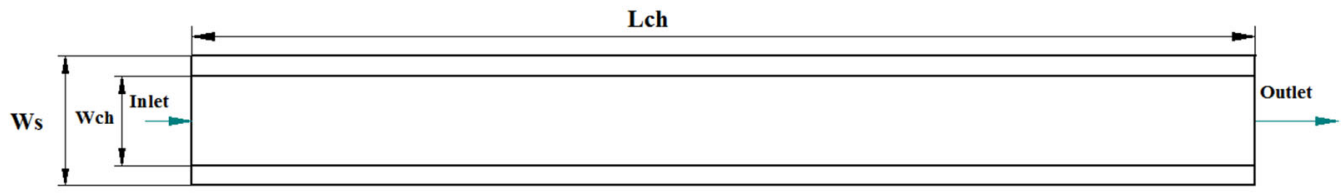

(b)

Figure 1. (a) Three-dimensional arrangement of unfinned micro channel heat sink. (b) Top view of single element micro channel heat sink. 

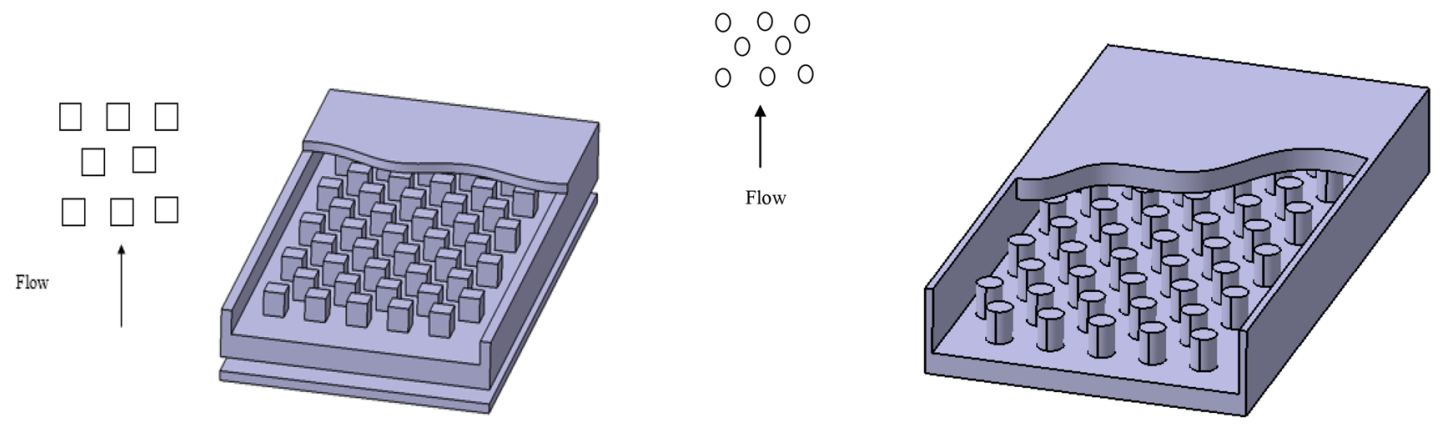

(a)

(c)

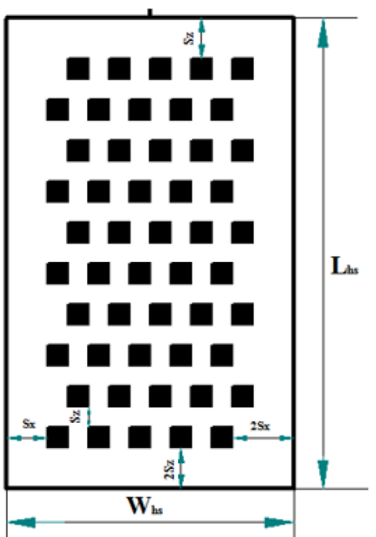

(b)
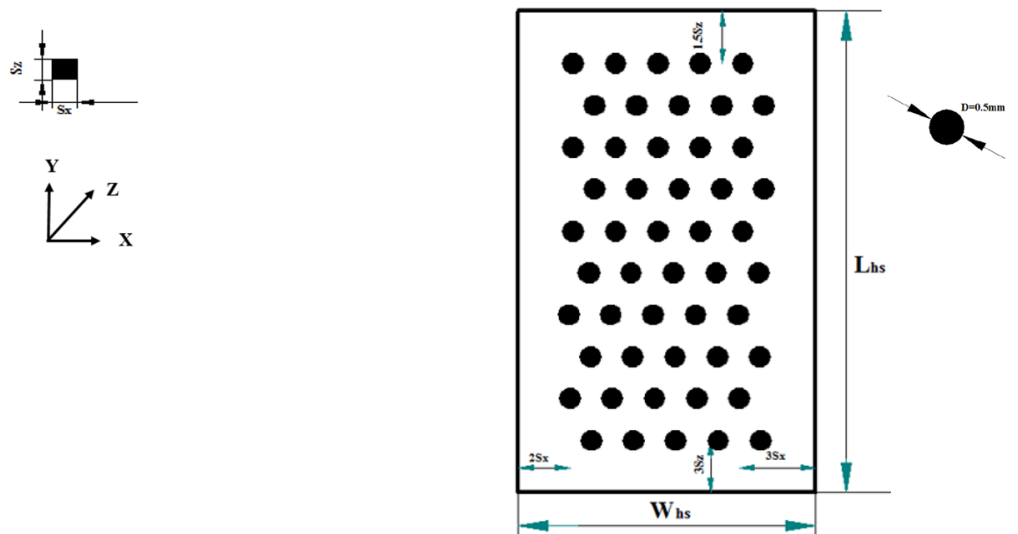

(d)

Figure 2. (a) Three-dimensional arrangement of staggered heat sink with square pin fin (HS-SPF). (b) Top view of Staggered arrangement of heat sink with circular pin fin. (c) Three-dimensional arrangement of staggered heat sink with circular pin fin(HS-CPF). (d) Top view of staggered arrangement of heat sink with circular pin fin.

investigation is to study the combined effect of pin fin heat sink and micro channel heat sink for different pin fin shapes.

\section{Description of physical model}

\subsection{Unfinned micro channel heat sink}

The three dimensional arrangement of unfinned micro channel heat sink and its top is shown in figure 1(a) and figure 1(b) respectively. An aluminum substrate of size $11.5 \mathrm{~mm} \times 6 \mathrm{~mm}$ with a total of 5 channels are considered for the present work. The geometrical parameters of rectangular micro channel heat sink are channel width $0.75 \mathrm{~mm}$ $\left(\mathrm{W}_{\mathrm{ch}}\right)$, Channel Height $1 \mathrm{~mm}\left(\mathrm{H}_{\mathrm{ch}}\right)$, heat sink width $1.125 \mathrm{~mm}\left(\mathrm{~W}_{\mathrm{s}}\right)$, Wall Thickness $0.375 \mathrm{~mm}(\mathrm{Wt})$, substrate thickness $0.375 \mathrm{~mm}$ (Ts). Owing to symmetric condition and to reduce the computational time, single element of micro channel heat sink is considered for computational model as shown in figure 1(b). Unfinned micro channel heat sink is considered to be the base line heat sink to compared the performance of pin fin heat sink and micro channel pin fin heat sink. This is taken as unfinned-MCHS.

\subsection{Pin fin heat sink}

A three-dimensional heat sink of dimensions $11.5 \mathrm{~mm} \times$ $6 \mathrm{~mm} \times 1 \mathrm{~mm}$ with 50 circular pin fins of diameter $0.5 \mathrm{~mm}$, height $0.5 \mathrm{~mm}$ and 50 square pin fins of size $0.5 \mathrm{~mm} * 0.5 \mathrm{~mm}$, height $0.5 \mathrm{~mm}$ is considered for square pin fin heat sink [HS-SPF] and circular pin fin heat sink [HS-CPF] as shown in figures 2(a), 2(b), 2(c) and 2(d), respectively . Further, staggered arrangement of fins spaced with distance of $0.5 \mathrm{~mm}$ is considered. Ten pin fins are considered in longitudinal direction and five in traverse direction. Longitudinal and transverse distance between pin fin are $\mathrm{Sx}=\mathrm{Sz}=0.5 \mathrm{~mm},[4]$.

\subsection{Micro channel pin fin heat sink}

A micro channel pin fin heat sink of size $11.5 \mathrm{~mm} \times 6 \mathrm{~mm}$ with a total of 5 channels are considered. The geometrical 


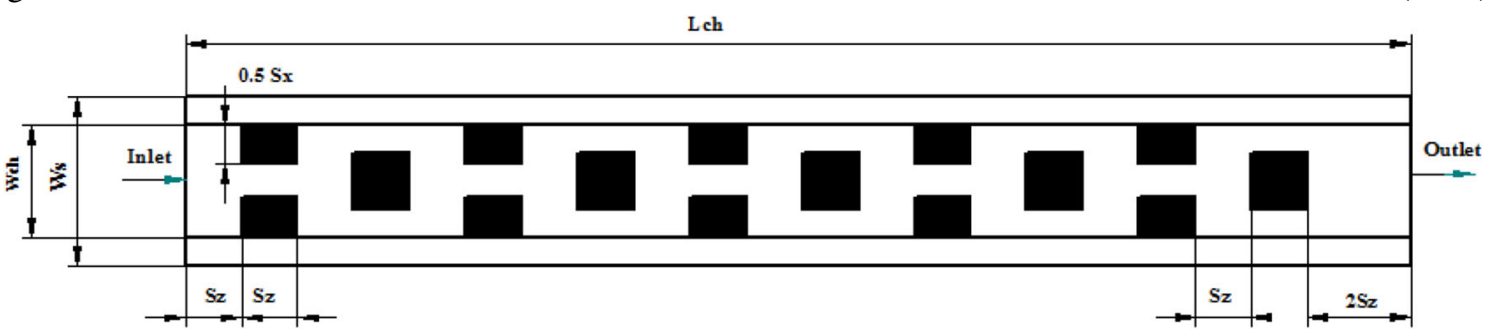

(a)

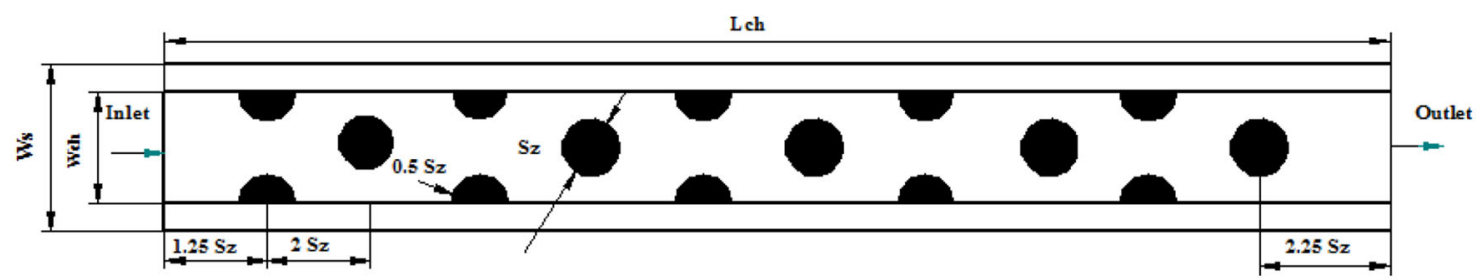

(b)

Figure 3. (a) Top view of single element micro channel heat sink with square pin fin (MCHS-SPF). (b)Top view of single element micro channel heat sink with circular pin fin (MCHS-CPF).

Table 1. Properties of coolant and heat sink.

\begin{tabular}{lcccc}
\hline & $\rho\left(\mathrm{kg} / \mathrm{m}^{3}\right)$ & $\mathrm{c}_{\mathrm{p}}(\mathrm{J} / \mathrm{kg}-\mathrm{K})$ & $\mathrm{K}(\mathrm{W} / \mathrm{m}-\mathrm{K})$ & $\mu(\mathrm{kg} / \mathrm{m}-\mathrm{s})$ \\
\hline Fluid (water) & 981.3 & 4189 & 0.643 & 0.000598 \\
Heat Sink & 2719 & 871 & 273 & - \\
\hline
\end{tabular}

parameters of micro channel pin fin heat sink are channel width $0.75 \mathrm{~mm}$ (Wch), Channel Height $1 \mathrm{~mm}$ (Hch), heat sink width $1.125 \mathrm{~mm}$ (Ws), Wall Thickness $0.375 \mathrm{~mm}$ (Wt), substrate thickness $0.375 \mathrm{~mm}(\mathrm{Ts})$. Ten pin fins are considered in the longitudinal direction. The dimensions of square pin fin are $0.5 \mathrm{~mm} \times 0.5 \mathrm{~mm}$ and diameter of circular pin fin is $0.5 \mathrm{~mm}$. The spacing fin distance are $\mathrm{Sx}=$ $0.125 \mathrm{~mm}$ and $\mathrm{Sz}=0.5 \mathrm{~mm}$, respectively. Owing to symmetric condition and to reduce the computational time, single element of micro channel pin fin heat sink is considered for computational model as shown in figures 3(a) and 3(b), respectively. To investigate flow and heat transfer characteristics of heat sink, water was used as working fluid and aluminum heat sink with constant properties [4] as shown in table 1 .

\subsection{Assumptions}

The following assumptions were made to simplify the problem

i) Flow is steady and laminar

ii) Fluid is Newtonian and incompressible

iii) No slip condition at walls.

iv) There is no viscous dissipation

v) Body forces are neglected.

\subsection{Governing Equation and parameter defnition}

Based on the above assumption, the following equation is solved to compute velocity and temperature distribution

Continuity equation

$$
\nabla \cdot(\rho \cdot V)=0
$$

Momentum equation

$$
(u . \nabla) \rho V=-\nabla P+\mu \nabla^{2} V
$$

Energy equation

$$
V . \nabla T=\frac{k}{\rho C_{p}} \nabla^{2} T
$$

Governing equation for heat sink is given by

$$
\nabla^{2} T=0
$$

Reynolds number at inlet is defined as

$$
\operatorname{Re}=\frac{\rho u d_{h}}{\mu}
$$

Where $\rho$ is the fluid density, $u$ is the inlet velocity, $d_{h}$ is the hydraulic diameter and $\mu$ is the fluid dynamic viscosity.

The maximum thermal resistance is evaluated using the relation

$$
R_{\max }=\frac{T_{\max }-T_{\text {in }}}{q}
$$

$\mathrm{T}_{\max }$ is the maximum temperature of the bottom substrate and $\mathrm{q}$ is the heat flux dissipated by the bottom substrate. 


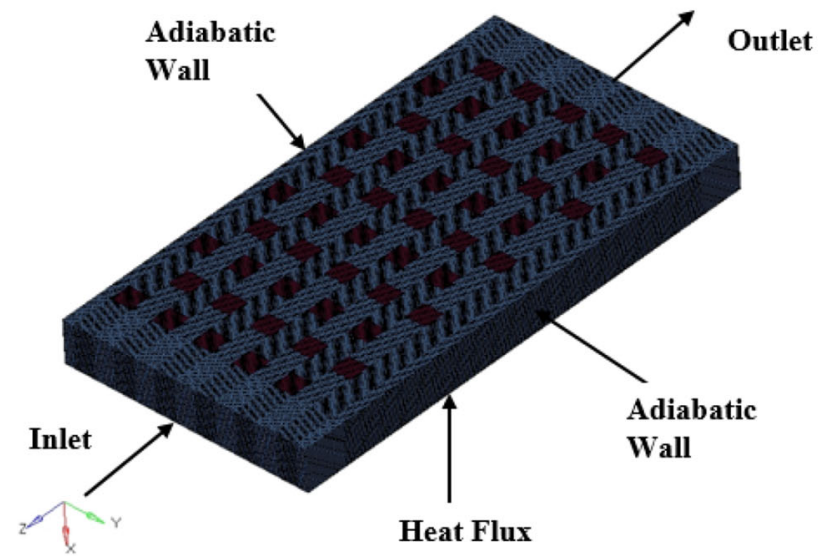

(a)

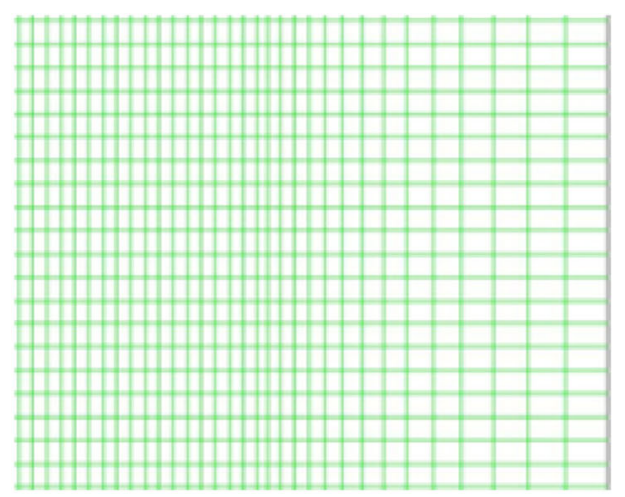

(b)

Figure 4. (a) Meshed configuration of square pin fin heat sink. (b) Zoomed view around pin fin.
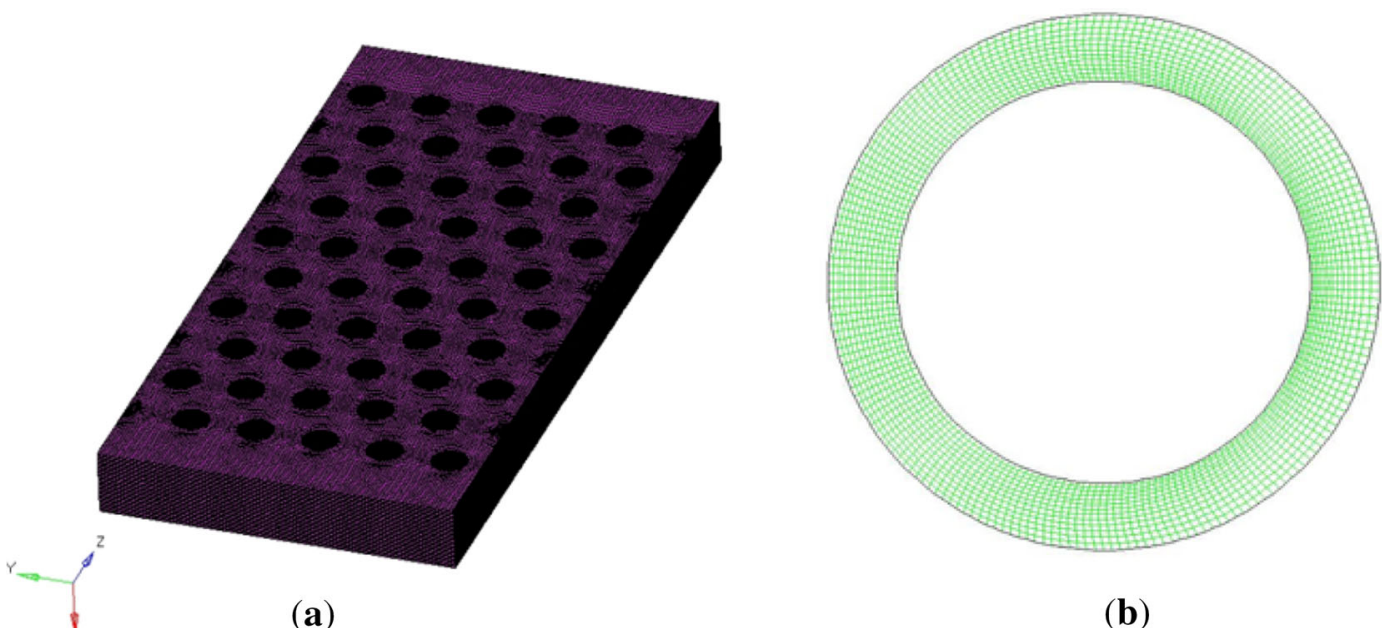

(b)

Figure 5. (a) Meshed configuration of circular pin fin heat sink. (b) Zoomed view around pin fin.

The average nusselt number is computed using the relation

$$
\begin{gathered}
N u=\frac{\mathrm{h}_{\mathrm{m}} \mathrm{d}_{\mathrm{h}}}{k} \\
h_{m}=\frac{Q}{n A\left(T_{\text {avg }}-T_{\text {in }}\right)}
\end{gathered}
$$

The required friction factor is calculated using the relation

$$
f=\frac{2 \cdot \Delta P}{\rho \cdot u_{\max }^{2}}
$$

The thermal-hydraulic performance of pin fin and micro channel pin fin heat sink is accessed using a non-dimensional parameter performance index, ratio of heat transfer enhancement to rise in pressure drop. unfinned micro channel is taken as the reference for comparison with other cases. Performance Index is given by

$$
\eta=\frac{N u / N u_{o}}{\left(\Delta P / \Delta P_{o}\right)^{1 / 3}}
$$

\subsection{Computational grid and boundary condition}

All three-dimensional fluid flow and conjugate heat transfer analysis presented in this paper were carried out using FLUENT software. Hyper mesh was used as the computational grid generation tool. Computational domain for pin fin heat sink, unfinned micro channel heat sink and micro channel heat sink with pin fin has been discretized using 
Table 2. Mesh independent study.

\begin{tabular}{lcccc}
\hline Number of elements & Outlet temperature $(\mathrm{K})$ & Pressure drop (pa) & \% change in Temperature & $\%$ change in pressure \\
\hline $1,12,231$ & 323.62 & 13.61 & 0.1697 & 0.013768 \\
$1,52,224$ & 324.17 & 13.72 & 0.2032 & 0.012876 \\
$2,21,661$ & 324.83 & 13.98 & 0.0431 & 0.4274 \\
$5,41,234$ & 324.95 & 14.04 & 0.0461 & 0.4255 \\
$8,21,778$ & 325.12 & 14.09 & - & 0.494 \\
$11,64,912$ & 325.31 & 14.19 & - & 0.2815 \\
$14,26,121$ & 325.31 & 14.21 & - \\
\hline
\end{tabular}

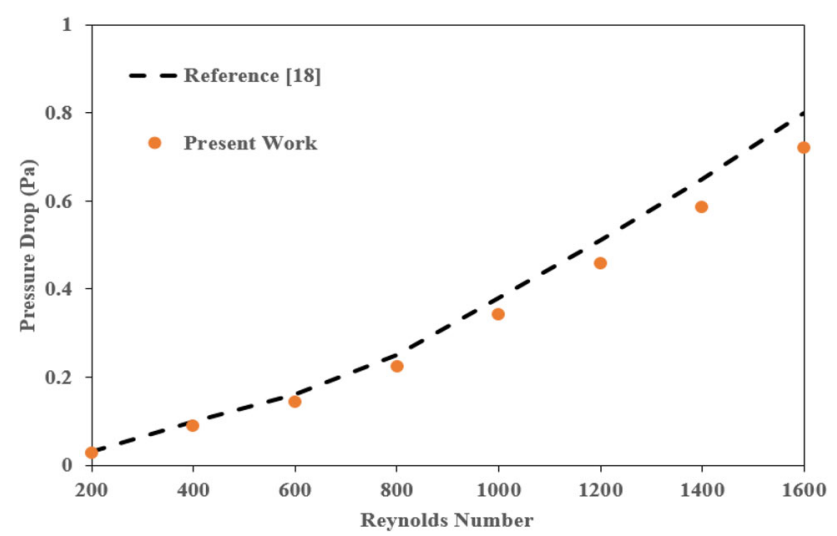

Figure 6. Comparison of pressure drop computed from the present work with experimental results [18].

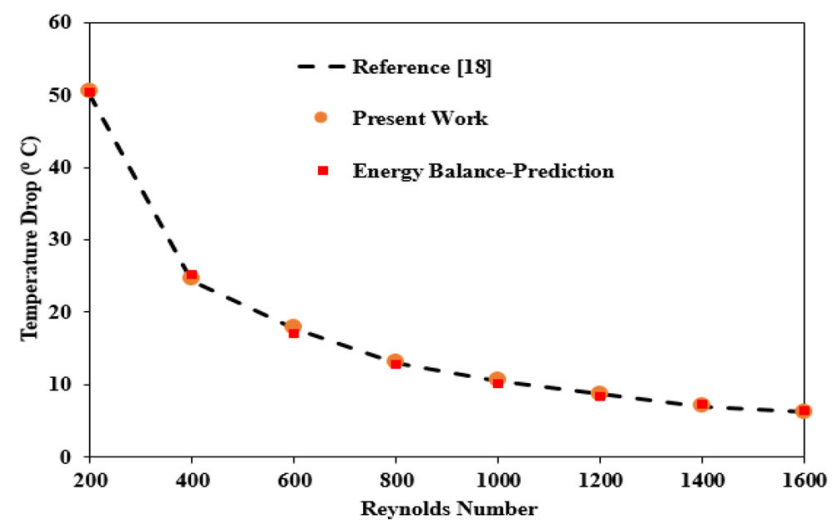

Figure 7. Comparison of temperature drop (Tout-Tin) computed from the present work with experimental results and energy balance values [18].

structured grids of hexahedral and few tetrahedron volume elements distributed uniformly, except near the finned surface. Finer mesh has been generated for pin fin walls with a cell ratio of 1.02 , as flow and heat transfer parameters are sensitive in this regions. For all the heat sink configuration, aspect ratio is less than 2, warp angle less than 5 degree. A sample mesh for staggered square and circular pin fin heat sink with zoomed view around the pin fin is shown in figures 4 and 5 , respectively.
The fluid velocity was computed based on flow Reynolds number $\operatorname{Re}=\frac{\rho u d_{h}}{\mu}$ and imposed at inlet where $d_{h}$ is the hydraulic diameter. The inlet fluid temperature at the entry was set to be Tin $=293 \mathrm{~K}$.

$$
\begin{aligned}
& \mathrm{u}=\mathrm{v}=0 \text { and } \mathrm{w}=\mathrm{w}_{\text {in }} \\
& \mathrm{T}=\mathrm{T}_{\text {in }}
\end{aligned}
$$

The flow is assumed to be fully developed at the outlet of the channel and zero velocity is defined at the solid boundaries. Uniform heat flux is imposed upon the bottom surface of the solid substrate, adiabatic condition was assumed for side walls in case of pin fin heat sink and symmetry condition for micro channel heat sink with pin fin, the upper wall was considered to be adiabatic. Thus, $\frac{\partial T}{\partial x}=0$ and $\frac{\partial T}{\partial y}=0$.

All heat sink configurations considered in the present study have same characteristic dimension. To have geometry has the only variable, the material characteristic of each pin fin is assumed to be same and uniform heat flux is applied at the bottom. The heat dissipation area for all the configuration discussed are kept constant.

\subsection{Solution methodology}

The governing conservative continuity, momentum and energy equations was solved using the Finite Volume Method. Convective terms was discretized using second order upwind scheme and a simple algorithm was adopted for pressure-velocity coupling to obtain the pressure field. Segregated solver was used to solve the conservation scheme. For convergence residual criteria $10^{-6}$ was used for continuity equation and velocity in all direction, whereas $10^{-7}$. for energy equation. The convergence criteria for conservative equations was set to $10^{-6}$. The entire work was carried out using FLUENT software.

\subsection{Mesh independence}

The grid independency was studied for heat sink with square pin fin with bottom wall temperature maintained at $373 \mathrm{~K}$ for Reynolds number 100 with pure water as coolant. 
Table 3. Temperature drop comparison between energy balance, experimental values with the present computation.

\begin{tabular}{cccc}
\hline & & Temperature drop $\left({ }^{\circ} \mathrm{C}\right)$ \\
\cline { 2 - 4 } Reynolds number & Energy balance & Experimental values [18] & Present computation \\
\hline 200 & 50.34 & 50.0 & 50.8 \\
400 & 25.17 & 24.4 & 24.82 \\
600 & 17.06 & 17.7 & 18.08 \\
800 & 12.86 & 13.0 & 13.3 \\
1000 & 10.06 & 10.6 & 10.75 \\
1200 & 8.39 & 8.7 & 8.85 \\
1400 & 7.27 & 7.0 & 7.14 \\
1600 & 6.43 & 6.3 & 6.375 \\
\hline
\end{tabular}

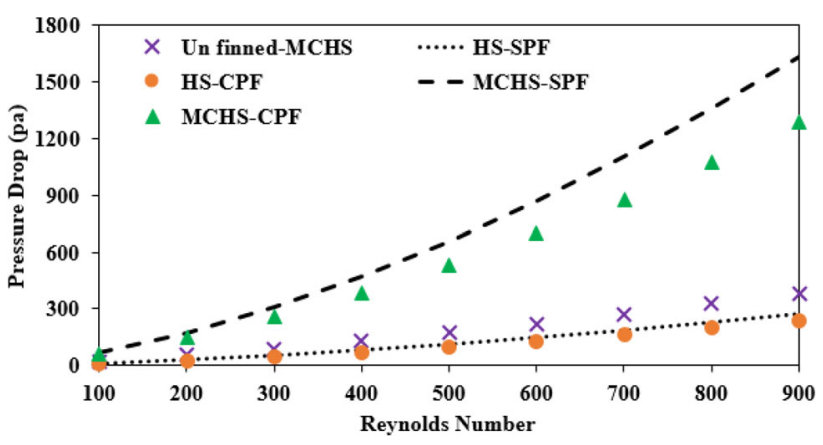

Figure 8. Variation of pressure drop with Reynolds number for different heat sink configurations.

To ensure grid independency of the results, a detailed study was carried out for various element size. The outlet temperature and pressure drop for different element size are tabulated in table 2 . The percentage change in outlet temperature and pressure drop between two successive grid sizes was around $0.04 \%$ for computational grid greater than 2, 21,661 elements. Hence a computational grid with 2, 21,661 elements was sufficient for the study, which gives same result with minimum computational time and minimum memory requirement.

\section{Results and discussion}

\subsection{Validation}

The present work was validated with the experimental results from literature [18].The model presented consists of rectangular micro channel of dimensions $231 \mu \mathrm{m} \times 731$ $\mu \mathrm{m}$. Deionized water was employed as coolant and test was conducted for $100 \mathrm{~W} / \mathrm{cm}^{2}$ for Reynolds number ranging between 200 and 1600 . The difference between the present simulation and analytical solution was very negligible. The results are validated for pressure drop and temperature drop. Figure 6 shows comparison of computed pressure drop with experimental values for increasing Reynolds number. Since pressure drop is directly proportional to square of velocity, pressure drop increases with Reynolds number. Computed pressure drop from the present work slightly under predicts experimental values. The deviation may be due to losses with sudden expansion and contraction at entry and exit of micro channel. Which is not considered while carrying out computational work.

Figure 7 shows comparison of measured temperature drop with experimental values and analytical values obtained from energy balance. $P_{w}=\rho_{f} C_{p f}\left(T_{\text {out }}-T_{\text {in }}\right)$.

The numerically measured temperature drop decreases with Reynolds number and are in good agreement with experimental results and analytical values, indicating power supplied by heater are effectively removed by water and heat losses are negligible. Table 3 shows the comparison of computed temperature drop with experimental and analytical value.

\subsection{Pressure drop and friction factor}

Figure 8 illustrates variation of pressure drop (difference between upstream and downstream pressure) with Reynolds number for different cases discussed above. As expected, pressure drop in micro channel pin fin heat sink is high compared to pin fin heat sink and unfinned micro channel heat sink. In case of unfinned micro channel heat sink, when working fluid flows inside confined channel, the viscous shear effect produced due to side walls is highly dominant and contributes to total pressure drop. It can be observed that MCHS-SPF has largest pressure drop compared to other cases. Both form drag and friction drag contribute to total pressure drop. When fluid passes around sharp corners, as in case of HS-SPF and MCHS-SPF, the flow around pin fin leads to form drag, the combined effect of viscous shear and separation around sharp corner contribute to increase in total pressure drop. Whereas due to stream line separation in HS-CPF and MCHS-CPF, pressure drop is slightly less than square pin fin. For all the cases pressure drop is minimum for lower flow velocity and increases with flow velocity. At low velocity, fluid viscosity and pin fin surface are responsible for boundary layer formation around pin fin. Wall effects are highly significant 


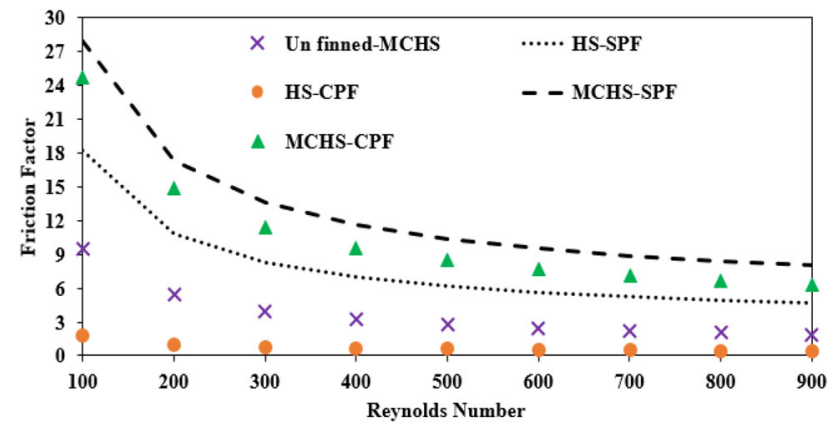

Figure 9. Variation of friction factor with Reynolds number for different heat sink configurations.

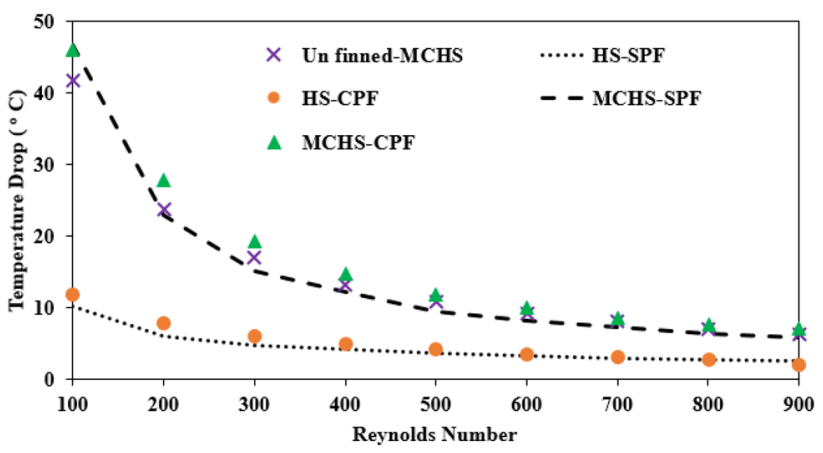

Figure 10. Variation of temperature drop with Reynolds number for different heat sink configurations.

and high wall shear stress is responsible for pressure drop [12].

On the other hand, the wall effects become weaker and insignificant with increases in flow velocity, the force exerted by fluid due to pin fin surface increases, leading to boundary layer separation from pin fin surface and vortex formed are shed into wake resulting in very rapid rise in pressure drop. Pressure drop for MCHS-CPF increases by 63\% in comparison with HS-CPF and for MCHS-SPF it increases by $58 \%$ in comparison with HS-SPF, respectively. Hence pressure drop increases with Reynolds number for all cases.

Friction factor decreases with Reynolds number, however at certain Reynolds number it reaches a constant value and remain constant thereafter. This trend is observed for all cases and are slightly inconsistent which is mainly due to the influence of different forces. The total forces exerted by fluid around solid surface is sum of forces exerted due to shear stress along flow direction namely frictional resistance and swirl resistance generated due to asymmetrical pressure distribution. At low flow velocity, frictional resistance is more compared to swirl resistance, due to the absence of vortex shedding the resistance offered is mainly due to friction. Due to inverse pressure gradient and end wall effect, separation occurs at high Reynolds number leading to vortex generation which is carried away from wake zone. The effect of swirl resistance increases with Reynolds number and becomes more dominant compared to frictional resistance. Hence frictional factor decreases with Reynolds number and remain constant due to inertia. Circular pin fin is more stream lined leading to delay in boundary layer separation and smaller wake zone compared to square pin fin as shown in figure 9. The effect of larger surface area can be the reason behind the larger pressure drop due to the friction drag [27].

\subsection{Temperature drop}

Figure 10 shows the temperature drop with Reynolds number for different cases discussed above. At low flow velocity fluid travels at slower rate absorbing maximum heat from heat sink resulting in rise in outlet temperature. Whereas at high flow velocity fluid travels at faster rate absorbing minimum heat leading to minimum rise in bulk temperature. At low Reynolds number heat transfer due to diffusion plays a key role for rise in outlet temperature and forced convection heat transfer plays a key role for drop in outlet temperature at high Reynolds number [28]. Flow around HS-CPF and MCHS-CPF is more stream lined, leading to better fluid mixing, which increases bulk temperature at outlet. Whereas in case of square pin fin, fluid flow is accelerated due to separation at sharp corners leading to drop in outlet temperature as seen in HS-SPF and MCHS-SPF. Hence Temperature drop for circular pin fin is slightly on the higher side compared to square pin fin for both pin fin heat sink and micro channel pin fin heat sink.

\subsection{Maximum thermal resistance}

Figure 11 shows variation of maximum thermal resistance with Reynolds number for different configurations of heat sink. For all cases of heat sink, thermal boundary layer thickness decreases with Reynolds number resulting in maximum heat transfer thereby decrease in thermal resistance. For flow around HS-SPF and MCHS-SPF, fluid separates around sharp corners triggering flow separation and promoting fluid mixing [12]. The wakes formed around square pin fin are large compared to circular pin fin leading to decrease in thermal resistance as shown in figures 14 and 15.

Maximum thermal resistance for MCHS-SPF and MCHS-CPF are low compared to HS-SPF and HS-CPF. The main reason is that, in case of micro channel heat sink with pin fin the combined effect of axial conduction phenomenon along flow direction and forced convection leads to decrease in thermal resistance; whereas the axial conduction effect is highly negligible for pin fin heat sink leading to increase in thermal resistance. This shows that axial conduction plays a key role in enhancing heat transfer for micro scale [8]. Thermal resistance for MCHS-SPF 


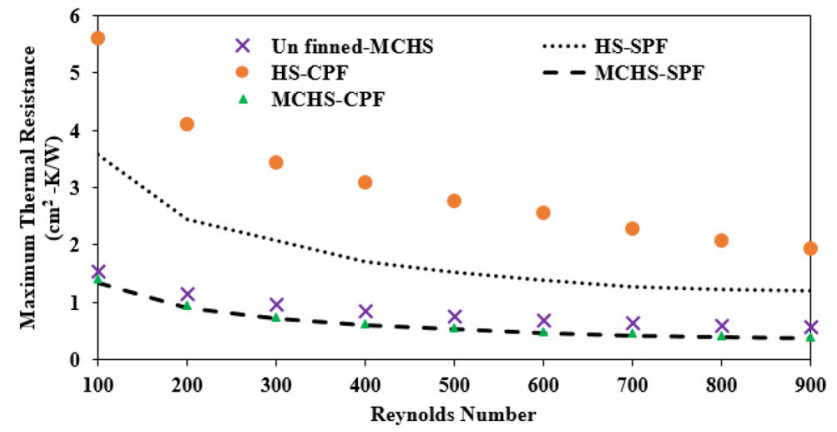

Figure 11. Variation of thermal resistance with Reynolds number for different heat sink configurations.

decreases by $42 \%$ in comparison with HS-SPF whereas for MCHS-CPF decreases by $57 \%$ compared to HS-CPF.

\subsection{Flow pattern}

Figures 12 and 13 illustrate temperature distribution and velocity distribution slice taken from the centre line along the symmetry plane for different cases. The temperature at the entry is $293 \mathrm{~K}$ everywhere. The temperature rise starts at the upstream point of the flow domain, and the heated fluid layer becomes thicker as it gets closer to the outlet as shown in figure 12 . While the temperature for different cases would certainly change along the longitudinal direction. For all cases, temperature distribution is maximum at the corner of heat sink since there is negligible amount of heat dissipation due to convection. The minimum temperature occurs at the entry of heat sink which is mainly due to higher heat transfer coefficient at the entry. The presence of pin fin interrupts the temperature profile and does not allow the boundary layer to grow to fully developed state as shown in figure 12. Due to flow interruption there is a redevelopment in thermal boundary layer resulting in better fluid mixing thereby increasing heat transfer. Along with this heat transfer is further enhanced due to the presence of pin fins.

Figure 13 indicates the average flow velocity is high for MCHS-SPF and MCHS-CPF compared to HS-SPF and HSCPF. Higher flow velocity brings about more heat transfer from hot surface to coolant thereby contributing to enhancement in heat transfer which in turn reduces the surface temperature of heat sink.

The stream line across MCHS-SPF and MCHS-CPF for different Reynolds number is shown in figures 14 and 15 . When the flow velocity increases, the force exerted by fluid from, pin fin surface increases leading to flow separation around pin fin and wake formation. Increase in flow velocity promotes flow separation leading to increase in larger wake zone [3]. From the stream line contour it is very clear that secondary vortices are formed for both MCHS-
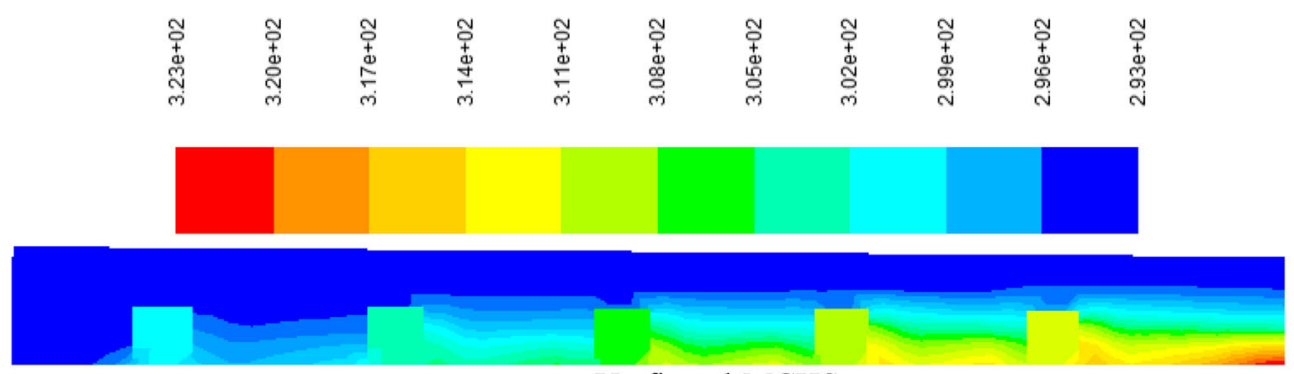

(i) Un finned-MCHS

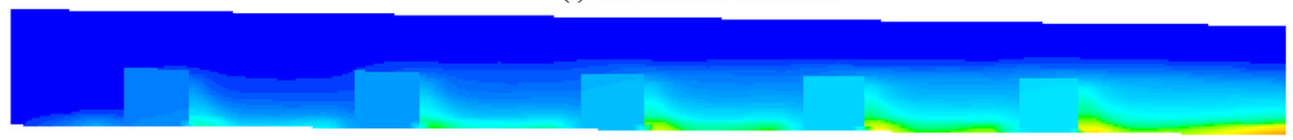

(ii) HS-SPF

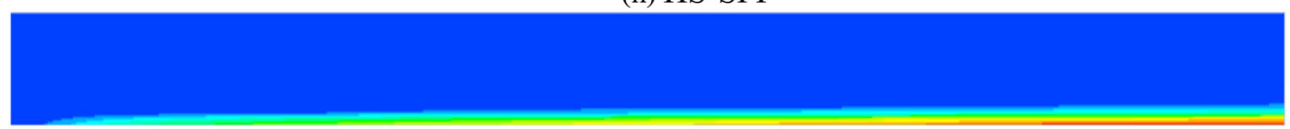

(iii) HS-CPF

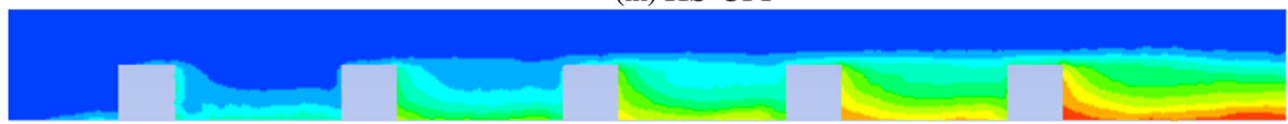

(iv) MCHS-SPF

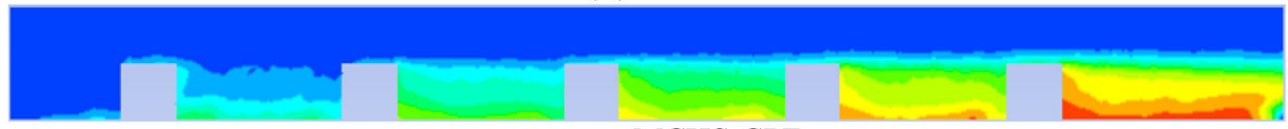

(v) MCHS-CPF

Figure 12. Temperature $(\mathrm{K})$ contour along the symmetric plane passing through central vertical line for different heat sink configurations. 


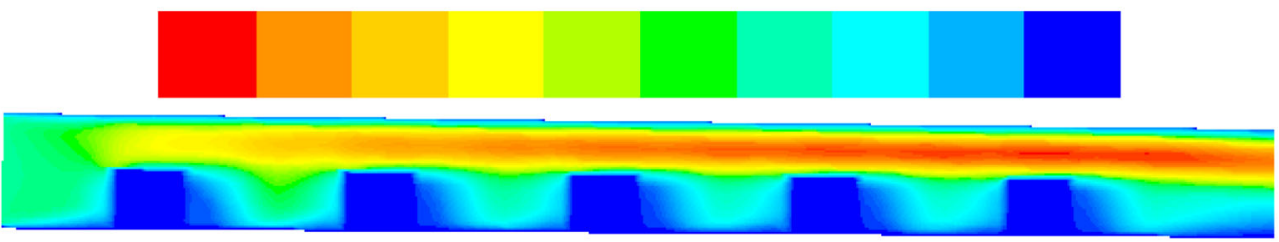

(i) Un finned-MCHS

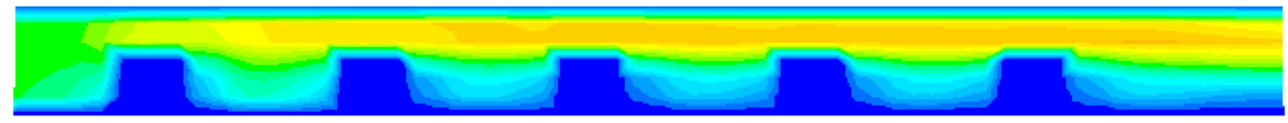

(ii) HS-SPF

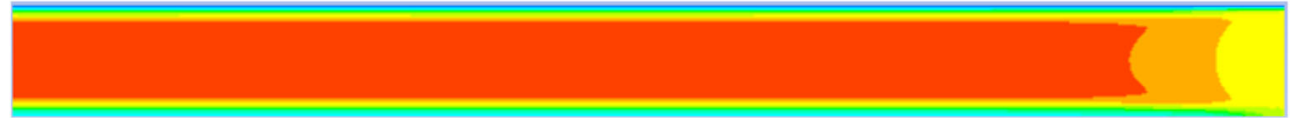

(iii) HS-CPF

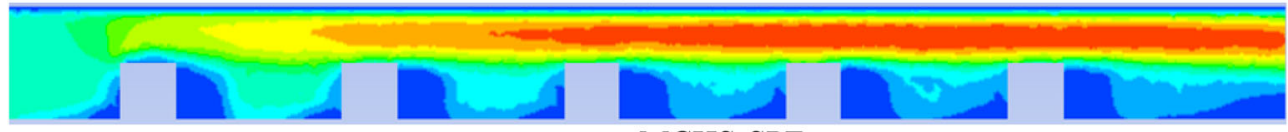

(iv) MCHS-SPF

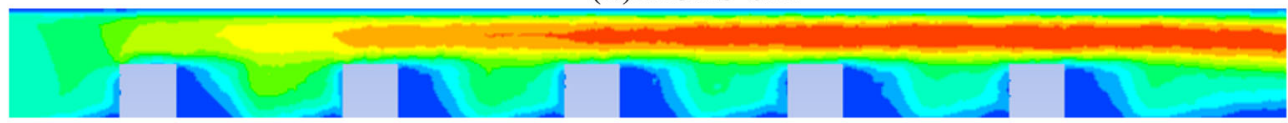

(v) MCHS-CPF

Figure 13. Velocity $(\mathrm{m} / \mathrm{s})$ contour along the symmetric plane passing through central vertical line for different heat sink configurations.

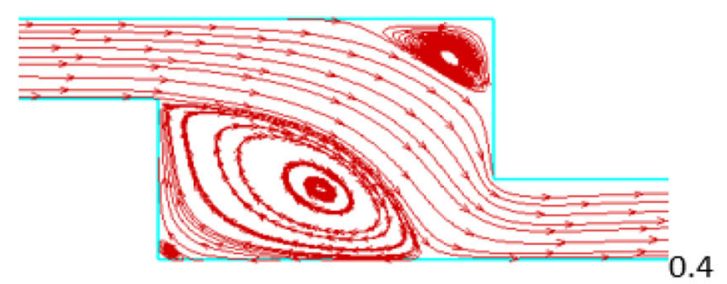

(a) $\operatorname{Re}=100$

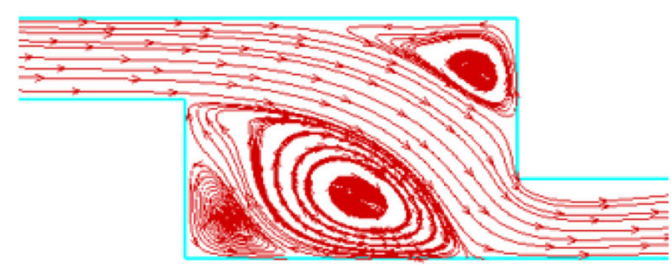

(c) $\mathrm{Re}=500$

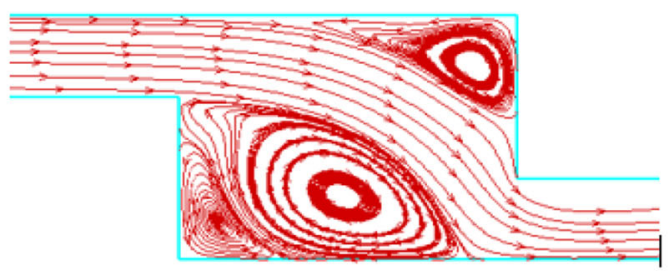

(e) $\operatorname{Re}=900$

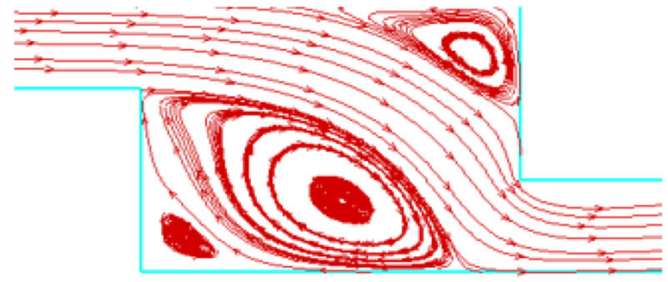

(b) $\operatorname{Re}=300$

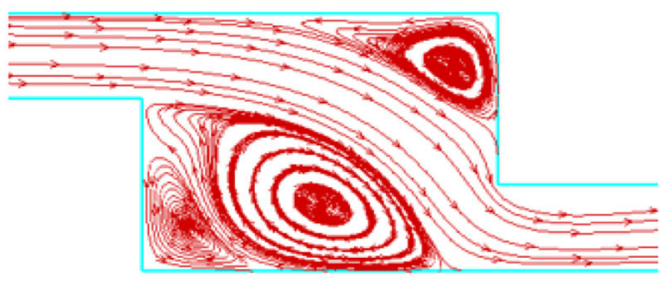

(d) $\operatorname{Re}=700$

Figure 14. Stream line contour with Reynolds number for MCHS-SPF. 


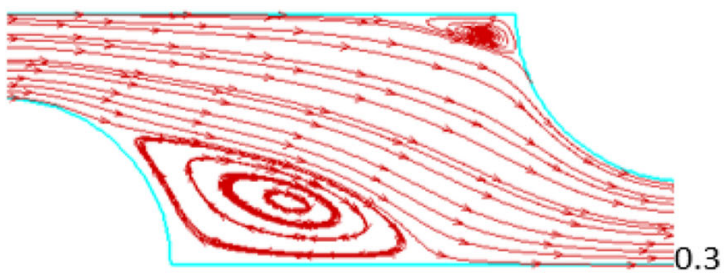

(a) $\operatorname{Re}=100$

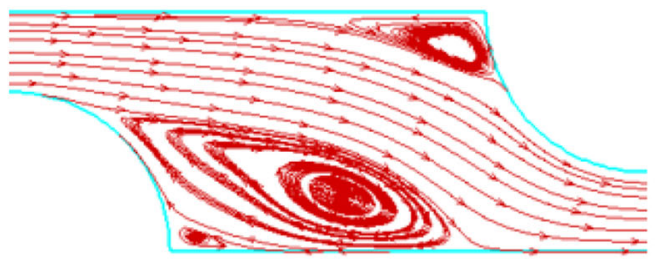

(c) $\operatorname{Re}=500$

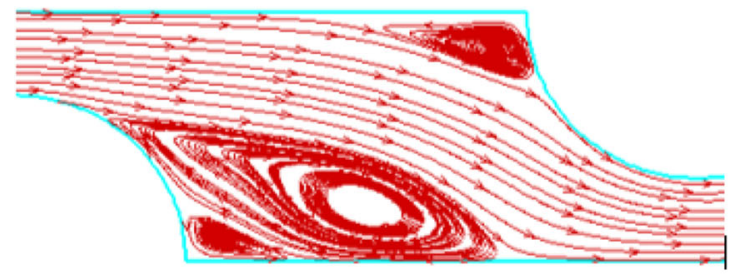

(e) $\operatorname{Re}=900$

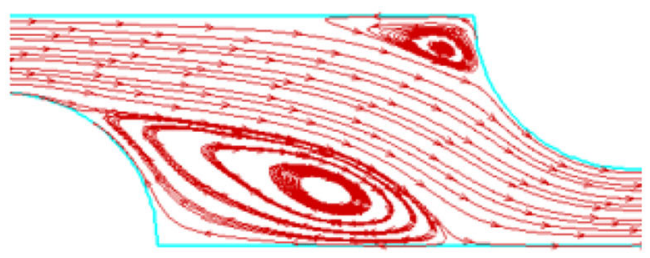

(b) $\mathrm{Re}=300$

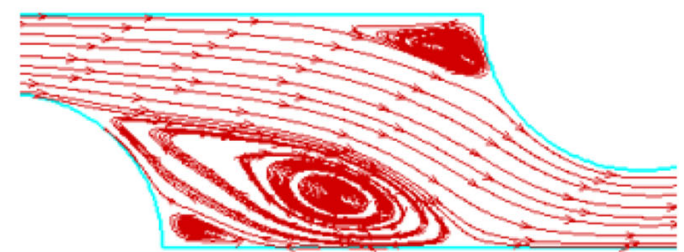

(d) $\mathrm{Re}=700$

Figure 15. Stream line contour with Reynolds number for MCHS-CPF.

SPF and MCHS-CPF, This may be due to the influence of turbulence promoting flow separation at low Reynolds number. Formation of secondary vortices is delayed for MCHS-CPF compared to MCHS-SPF due to stream line separation. When Reynolds number increases from 100 to 900 , length of recirculation zone increases from $0.38 * 10^{-3} \mathrm{~m}$ to $0.49 * 10^{-3} \mathrm{~m}$ for MCHS-SPF and $0.3 \times 10^{-3} \mathrm{~m}$ to $0.42 \times 10^{-3} \mathrm{~m}$ for MCHS-CPF. Recirculation zone is broader for pin fin with sharp corners compared to stream line separation showing pronounced flow separation leading to intense mixing of fluid resulting in heat transfer enhancement.

\subsection{Nusselt number}

Figure 16 demonstrates nusselt number as a function of Reynolds number for different cases. As expected nusselt number increases with Reynolds number for all the cases. Nusselt number for micro channel pin fin heat sink (MCHSSPF and MCHS-CPF) and pin fin heat sink (HS-SPF and HS-CPF) are high compared to unfinned-MCHS, which is mainly due to the presence of extended surfaces.

The temperature profile for HS-SPF, HS-CPF, MCHSSPF and MCHS-CPF is highly disrupted due to the presence of pin fins as shown in figures 12 and 13, thereby not

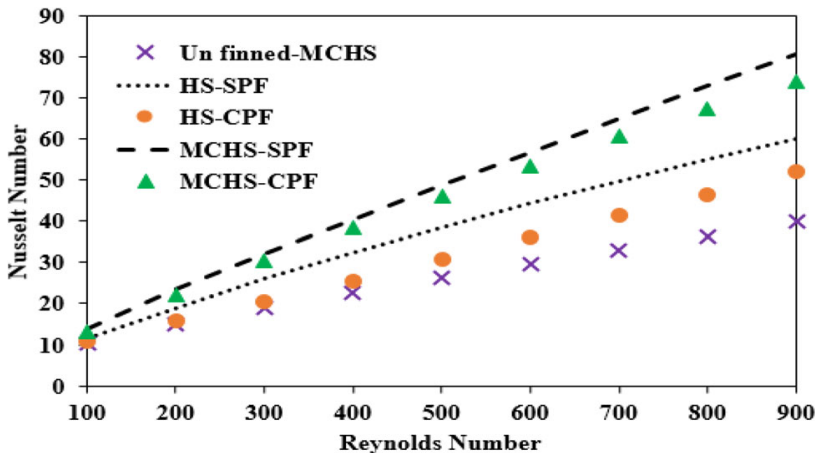

Figure 16. Variation of nusselt number with Reynolds number for different heat sink configurations.

allowing the thermal boundary layer to reach the fully developed state. This disruption is due to the presence of pin fins leads to redevelopment of thermal boundary layer [26], also the presence of pin fin intensifies flow separation absorbing maximum heat from solid pin fins and increasing heat transfer. The collective effect of redevelopment of boundary layer and better fluid mixing is responsible for increase in Nusselt number for heat sink with pins. The Nusselt number trend for pin fin heat sink is similar to the result obtained in numerical study by [3]. 
The performance of heat sink based on nusselt number form higher to lower value are in the order MCHS-SPF, MCHS-CPF, HS-SPF, HS-CPF and unfinned-MCHS. Pin fins with sharp corners triggers flow separation and has larger surface area compared to circular pin fin, hence heat sink with square pin fin performance is better compared to circular pin fin.

The main objective of the study was to decrease the maximum surface temperature and enhance high heat transfer rate. By employing micro channel with pin fin the conduction heat transfer can be highly enhanced compared to pin fin heat sink resulting in higher heat transfer rate thereby reducing surface temperature. The values of pressure drop and nusselt number for various heat sink configuration are provided in table 4.

\subsection{Thermal performance index}

The presence of extended surface in pin fin heat sink and micro channel pin fin heat sink has better heat transfer performance compared to unfinned micro channel with rise in pressure drop. Hence a non-dimensional parameter namely thermal performance index (TPI) is defined to study the overall performance of pin fin heat sink and micro channel heat sink by comparing with unfinned micro channel. Thermal performance index is defined as $\eta=\frac{N u / N u_{o}}{\left(\Delta P / \Delta P_{o}\right)^{1 / 3}}$. Figure 17 shows the variation of thermal performance index with Reynolds number subjected to $10 \mathrm{~W} / \mathrm{cm}^{2}$. This clearly shows the overriding rise in overall pressure drop compared to increase in heat transfer. For fluid flow in MCHS-SPF and MCHS-CPF the intensity of velocity fluctuation is more rapid compared to HS-SPF and HS-CPF. Micro channel pin fin heat sink (MCHS-SPF and MCHS-CPF) are highly sensitive to end wall effect the same penetrates to main flow more rapidly compared to pin fin heat sink (HS-SPF and HS-CPF) leading to increase in pressure drop. Hence in terms of TPI, pin fin heat sink are

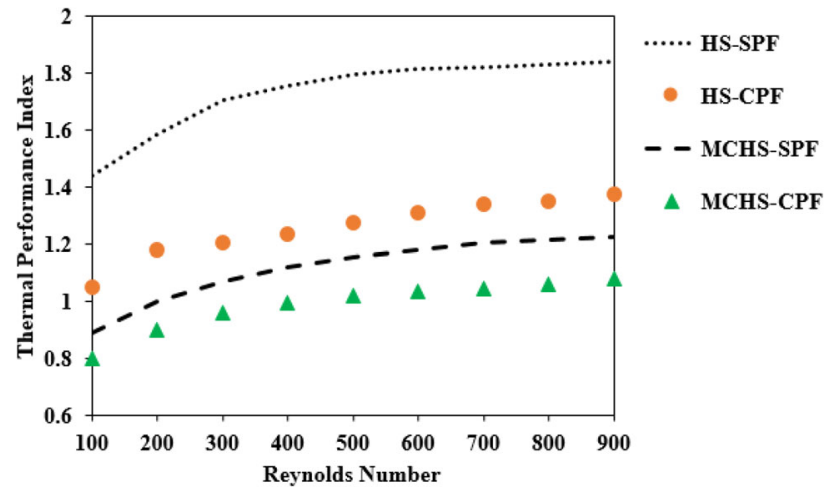

Figure 17. Thermal performance index with Reynolds number for different heat sink configurations.

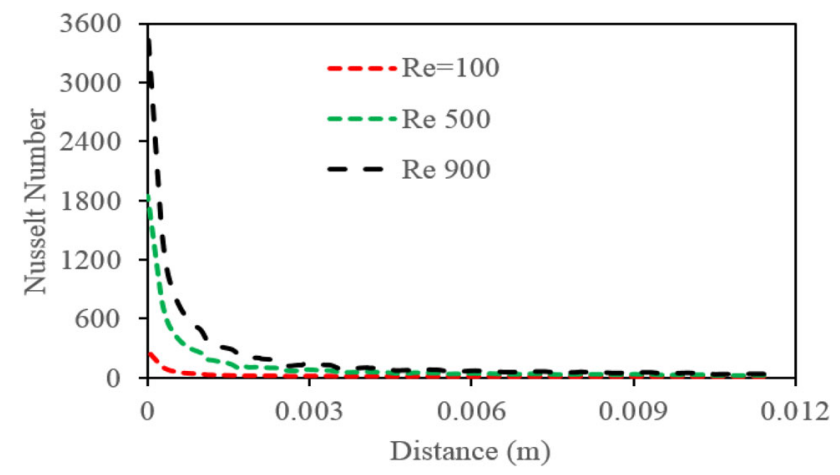

Figure 18. Variation of Nusselt number along the length of channel for different Reynolds number for MCHS-SPF.

considered to be superior compared to micro channel pin fin heat sink.

\subsection{Local Nusselt number and friction factor for micro channel pin fin heat sink}

Figures 18 and 19 illustrate variation of local Nusselt number along the length of micro channel heat sink for

Table 4. Comparison of pressure drop and nusselt number for various heat sink configuration.

\begin{tabular}{|c|c|c|c|c|c|c|c|c|c|c|}
\hline \multirow[b]{2}{*}{$\begin{array}{l}\text { Reynolds } \\
\text { number }\end{array}$} & \multicolumn{2}{|c|}{ Un finned MCHS } & \multicolumn{2}{|l|}{ HS-SPF } & \multicolumn{2}{|l|}{$\mathrm{HS}-\mathrm{CPF}$} & \multicolumn{2}{|c|}{ MCHS-SPF } & \multicolumn{2}{|c|}{ MCHS-CPF } \\
\hline & $\begin{array}{l}\text { Pressure drop } \\
\qquad(\mathrm{Pa})\end{array}$ & $\mathrm{Nu}$ & $\begin{array}{l}\text { Pressure drop } \\
(\mathrm{Pa})\end{array}$ & $\mathrm{Nu}$ & $\begin{array}{l}\text { Pressure drop } \\
\qquad(\mathrm{Pa})\end{array}$ & $\mathrm{Nu}$ & $\begin{array}{l}\text { Pressure drop } \\
(\mathrm{Pa})\end{array}$ & $\mathrm{Nu}$ & $\begin{array}{l}\text { Pressure drop } \\
(\mathrm{Pa})\end{array}$ & $\mathrm{Nu}$ \\
\hline 100 & 24.04 & 10.20 & 13.04 & 11.55 & 11.47 & 10.78 & 70.68 & 14.02 & 62.23 & 13.12 \\
\hline 200 & 54.29 & 15.13 & 31.65 & 18.95 & 27.32 & 15.81 & 174.56 & 23.43 & 149.64 & 22.17 \\
\hline 300 & 89.57 & 19.09 & 54.48 & 26.08 & 47.03 & 20.62 & 308.30 & 32.18 & 259.05 & 30.55 \\
\hline 400 & 129.05 & 22.72 & 81.50 & 32.36 & 70.55 & 25.57 & 468.69 & 40.56 & 387.22 & 38.44 \\
\hline 500 & 172.12 & 26.17 & 112.51 & 38.55 & 97.60 & 30.76 & 654.69 & 48.75 & 533.94 & 46.13 \\
\hline 600 & 220.27 & 29.62 & 145.43 & 44.34 & 128.14 & 35.97 & 867.44 & 56.88 & 697.87 & 53.40 \\
\hline 700 & 269.86 & 32.94 & 186.12 & 49.70 & 162.11 & 41.40 & 1100.83 & 64.95 & 878.16 & 60.65 \\
\hline 800 & 326.42 & 36.46 & 228.44 & 55.01 & 199.52 & 46.41 & 1359.09 & 72.94 & 1075.99 & 67.24 \\
\hline 900 & 382.65 & 39.83 & 274.42 & 59.91 & 240.32 & 52.16 & 1634.64 & 80.80 & 1287.16 & 73.94 \\
\hline
\end{tabular}




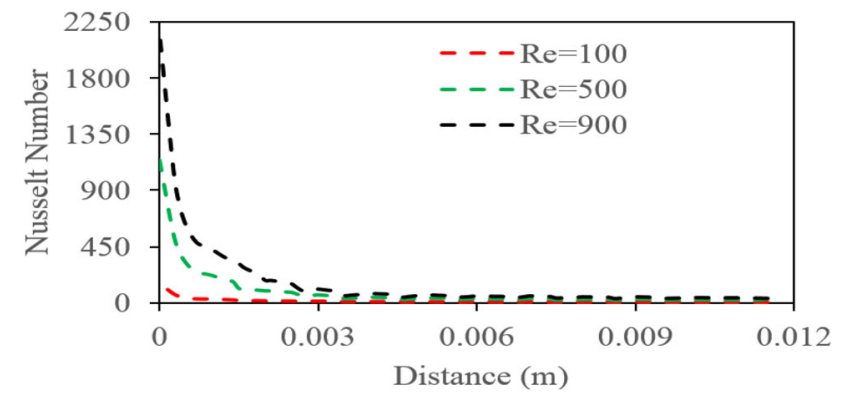

Figure 19. Variation of Nusselt number along the length of channel for different Reynolds number for MCHS-CPF.

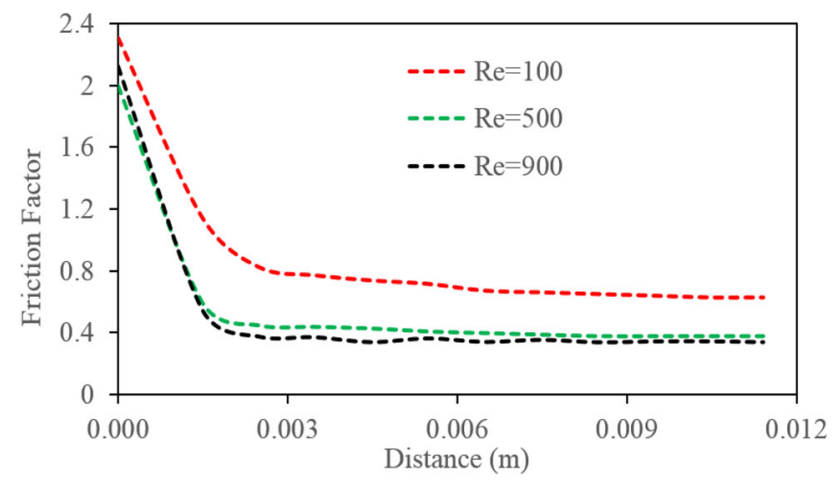

Figure 20. Variation of friction factor along the length of channel for different Reynolds number for MCHS-SPF.

MCHS-SPF and MCHS-CPF. Nusselt number is very large at the entry of channel and decreases to a constant value along the flow direction due to thinning boundary layer approaching fully developed flow. As Reynolds number increases thermal developing length shift towards right for both cases whereas developing length is slightly delayed for MCHS-SPF this may be due to wake effect. The thermally entry length ratio [29] $\left(\mathrm{L}_{\mathrm{thr}}=\mathrm{L}_{\mathrm{th}} / \mathrm{L}\right)$ increase from 0.17 to 0.78 and 0.15 to 0.65 for MCHS-SPF and MCHS-CPF with rise in Reynolds number from 100 to 900, respectively.

Due to entrance effect in MCHS-SPF friction factor is very large at entry compared to MCHS-CPF and reaches a constant value at the exit of channel approaching

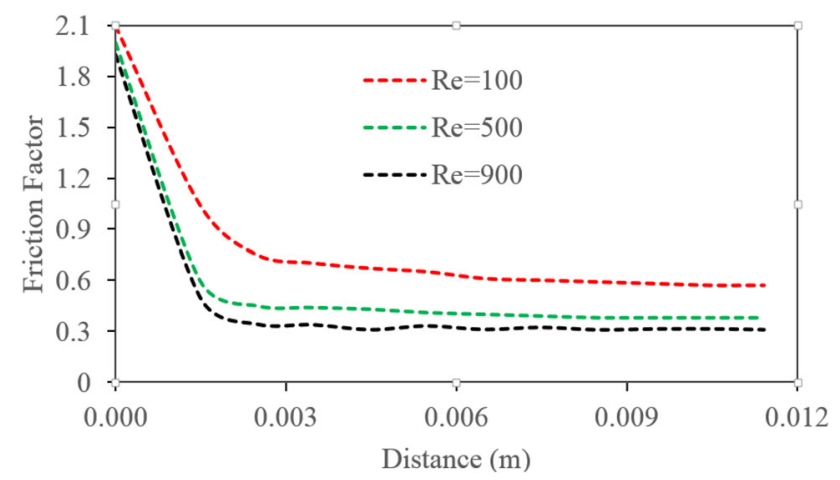

Figure 21. Variation of friction factor along the length of channel for different Reynolds number for MCHS-CPF. hydrodynamic fully developed flow. For Reynolds number 100 the flow is assumed to be hydro dynamic by a value $0.007 \mathrm{~m}$ and $0.0072 \mathrm{~m}$ for MCHS-SPF and MCHS-CPF as shown in figures 20 and 21. This shows that the sufficient length of micro channel heat sink is in the entrance region. Hydrodynamic entrance length increases with Reynolds number and implies that the hydrodynamic entrance effect is extended along the channel.

\section{Conclusion}

In the present work, experimentally tested system were numerically modelled at Reynolds number between 200 and 1600. The numerical results were compared with experimental data to show the credibility of numerical method. Later, thermal hydraulic performance of pin fin heat sink and micro channel pin fin heat sink was compared with unfinned micro channel heat sink based on pressure drop, friction factor, nusselt number, performance index and stream contours.

The novelty of the present work lies in the fact that, the combined effect of micro channel heat sink with different pin fin shapes are examined to show its effect on thermalhydraulic performance and compared with pin fin heat sink.

Based on the present work the following conclusions were drawn.

1. The combined effect of axial conduction and forced convection plays a key role in decreasing maximum thermal resistance for MCHS-SPF and MCHS-CPF. Maximum thermal resistance for MCHS-SPF decreases by $42 \%$ compared to HS-SPF and for MCHS-CPF it decreases by $57 \%$ compared to HS-CPF, respectively. MCHS-SPF and MCHS-CPF are observed to be far superior when compared to pin fin heat sink (HS-SPF and HS-CPF) in terms of heat transfer enhancement, indicating that the micro channel pin fin heat sink can be significantly a better alternative for pin fin heat sink.

2. The effective convective heat transfer gives importance to elucidating means for incorporating various pin fin shapes and increase in flow rates. However, the presence of pin fins and high flow rates necessitate higher pressure drop. Thus pressure drop is a major concern during the design of heat sink. Further, more efforts are made to develop better heat sink configurations which significantly enhances heat transfer with minimum pressure drop. Hence a non-dimensional parameter namely, thermal performance index based on unfinned micro channel heat sink increases with Reynolds number and HS-SPF has highest performance index compared to other heat sink configuration, which shows that HS-SPF would be a better alternative when combined effect of heat transfer and pressure drop are considered.

3. The formation of secondary vortices for MCHS-SPF has strong influence on enhancement of heat transfer 
compared to MCHS-CPF. The Thermal entry length for MCHS-SPF is slightly delayed due to wake formation and study shows that sufficient hydrodynamic length of channel is within the entrance region for both MCHSSPF and MCHS-CPF. Recirculation zone is broader for pin fin with sharp corners compared to stream line separation showing pronounced flow separation leading to intense mixing of fluid resulting in heat transfer enhancement.

4. At low velocity, the presence of pin fin has little influence on flow and is evident at high velocity. The pressure drop increases with flow velocity and is sufficiently large for fluid flow with sharp separation compared to stream line separation for both micro channel pin fin heat sink and pin fin heat sink. Pressure drop for MCHS-CPF increases by $63 \%$ compared to HSCPF whereas for MCHS-SPF it increases by $58 \%$ compared to HS-SPF.

5. The water outlet temperature and temperature with in heat sink for all configurations could be greatly reduced at higher Reynolds numbers with penalty in pressure drop.

$\begin{array}{ll}\text { Nomenclature } \\ \mathrm{A} & \text { Cross sectional area }\left(\mathrm{m}^{2}\right) \\ \mathrm{m} & \text { Mass flow rate }(\mathrm{kg} / \mathrm{s}) \\ \mathrm{d} & \text { Diameter }(\mathrm{m}) \\ \mathrm{C} & \text { Specific heat }(\mathrm{J} / \mathrm{kg}-\mathrm{K}) \\ \mathrm{H} & \text { Height of fin } \\ \mathrm{h} & \text { Heat Transfer co efficient }\left(\mathrm{W} / \mathrm{m}^{2}-\mathrm{K}\right) \\ \mathrm{K} & \text { Thermal conductivity }(\mathrm{W} / \mathrm{m}-\mathrm{K}) \\ \mathrm{L} & \text { Length } \\ \mathrm{Nu} & \text { Nusselt Number } \\ \mathrm{Q} & \text { Heat dissipated }(\mathrm{W}) \\ \mathrm{Re} & \text { Reynolds Number } \\ \mathrm{p} & \text { Constant Pressure } \\ \mathrm{u}, \mathrm{v} \text { w } & \text { Velocity in } \mathrm{x}, \mathrm{y} \text { and } \mathrm{z} \\ \mathrm{V} & \text { Velocity component }(\mathrm{m} / \mathrm{s}) \\ \mathrm{Sx} \text { and } \mathrm{Sz} & \text { spacing distance } \\ \mathrm{w} & \text { width } \\ \mathrm{f} & \text { fin }\end{array}$

\section{Greek symbols}

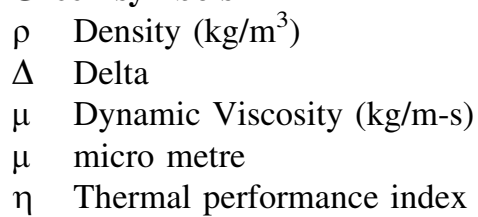

\begin{tabular}{ll}
\multicolumn{2}{l}{ Subscripts } \\
$\mathrm{P}$ & Pressure $(\mathrm{Pa})$ \\
$\mathrm{h}$ & Hydraulic \\
in & Inlet \\
out & Outlet
\end{tabular}

$\begin{array}{ll}\text { avg } & \text { Average } \\ \text { Sur } & \text { Surface } \\ \text { f } & \text { fluid } \\ \text { th } & \text { Thermally developing } \\ \text { thr } & \text { Entry length ratio } \\ \text { t } & \text { traverse } \\ 1 & \text { longitudinal } \\ \text { ch } & \text { channel } \\ \text { s } & \text { sink } \\ \text { o } & \text { un finned micro channel }\end{array}$

\section{References}

[1] Tuckerman D B and Pease R F W 1981 High-Performance Heat Sinking for VLSI, IEEE Electronic Device Letters, 2: 126-129

[2] Haleh Shafeie, Omid Abouali, Khosrow Jafarpur and Goodarz Ahmadi 2013 Numerical study of heat transfer performance of single-phase heat sinks with micro pin-fin structures, Applied Thermal Engineering. 58: 68-76

[3] Turker Izcia, Mustafa Koza and Ali Koşara 2015 The Effect of Micro Pin-Fin Shape on Thermal and Hydraulic Performance of Micro Pin-Fin Heat Sinks, Heat Transfer Engineering, 36(7): 1447-1457

[4] Mushtaq I. Hasan 2014 Investigation of flow and heat transfer characteristics in micro pin-fin heat sink with nanofluid, Applied Thermal Engineering, 63(2): 598-607

[5] Sohail R Reddy, Abas Abdoli, George S, Dulikravich, Cesar C Pacheco, Genesis Vasquez, Rajesh Jha, Marcelo J Colaco and Helcio R B Orlande 2015 Multi-Objective Optimization Of Micro Pin-Fin Arrays For Cooling Of High Heat Flux Electronics With a Hot Spot. In: Proceedings of the ASME 2015 International Technical Conference and Exhibition on Packaging and Integration of Electronic and Photonic Microsystems and ASME

[6] Abas Abdoli, Gianni Jimenez and George S, Dulikravich 2015 Thermo-fluid analysis of micro pin-fin array cooling configurations for high heat fluxes with a hot spot, International Journal of Thermal Sciences, 90: 290-297

[7] Carlos A, Rubio-Jimenez, Satish G Kandlikar and Abel Hernandez-Guerrero 2012 Numerical Analysis of Novel Micro Pin Fin Heat Sink With Variable Fin Density. IEEE Transactions On Components, Packaging And Manufacturing technology, 2(5): 825-833

[8] Liu Z G,Guan N, Zhang C W and Jiang G L 2015 The Flow Resistance and Heat Transfer Characteristics of Micro PinFins with Different Cross-Sectional Shapes, Nanoscale and Microscale Thermo physical Engineering, 19:221-243

[9] Yoav Peles, Ali Kosar, Chandan Mishra, Chih-Jung Kuo and Brandon Schneider 2005 Forced convective heat transfer across a pin-fin micro heat sink, International Journal of Heat and Mass Transfer 48: 3615-3620

[10] Hongxia Zhao, Zhigang Liu, Chengwu Zhang, Ning Guan and Honghua Zhao 2016 Pressure drop and friction factor of a rectangular channel with staggered mini pin fins of different shapes. Experimental Thermal and Fluid Science, 71:57-69 
[11] John T J, Mathew B and Hegab H 2010 Parametric Study on the Combined Thermal and Hydraulic Performance of Single Phase Micro Pin-Fin Heat Sinks Part I: Square and Circle Geometries, International Journal of Thermal Science, 49: 2177-2190

[12] Kosar A and Peles Y 2006 Thermal-hydraulic performance of MEMS-based pin fin heat sink, ASME Journal of Heat Transfer, 128: 121-131

[13] Bayram Sahin and Alparslan Demir 2008 Performance analysis of a heat exchanger having perforated square fins, Applied Thermal Engineering, 28: 621-632

[14] Judy J, Maynes D andWebb BW 2002 Characterization of frictional pressure drop for liquid flows through micro channels, International Journal of Heat and Mass Transfer, 45: 3477-3489

[15] Poh-Seng Lee, Suresh V Garimella and Dong Liu 2005. Investigation of heat transfer in rectangular microchannels International Journal of Heat and Mass Transfer, 48:1688-1704

[16] Giulio Croce, Paola D'agaro and Carlo Nonino 2007 Threedimensional roughness effect on microchannel heat transfer and pressure drop International Journal of Heat and Mass Transfer, 50: 5249-5259

[17] Weilin Qu, Gh Mohiuddin Mala and Dongqing Li 2000 Heat transfer for water flow in trapezoidal silicon micro channels, International Journal of Heat and Mass Transfer, 43: 3925-3936

[18] Weilin Qu and Issam Mudawar 2002 Experimental and numerical study of pressure drop and heat transfer in a single-phase micro-channel heat sink International, Journal of Heat and Mass Transfer, 45: 2549-2565

[19] Dorin Lelea, Shigefumi Nishio and Kiyoshi Takano 2004 The experimental research on micro tube heat transfer and fluid flow of distilled water, International Journal of Heat and Mass Transfer, 47:, 2817-2830
[20] Reiyu Chein and Janghwa Chen 2009 Numerical study of the inlet/outlet arrangement effect on microchannel heat sink performance, International Journal of Thermal Sciences,48: $1627-1638$

[21] Todd M Harms, Michael J Kazmierczak and Frank M Gerner 1999 Developing convective heat transfer in deep rectangular microchannels, International Journal of Heat and Fluid Flow, 20: 149-157

[22] Gian Luca Morini 2004 Single-phase convective heat transfer in microchannels a review of experimental results, International Journal of Thermal Sciences, 43: 631-651

[23] Peng X F, Peterson G P andWang B X 1994 Frictional Flow Characteristics Of Water Flowing Through Rectangular micro channels, 7: 249-264

[24] Wu H Y andPing Cheng 2003 An experimental study of convective heat transfer in silicon micro channels with different surface conditions, International Journal of Heat and Mass Transfer, 46: 2547-2556

[25] Fengli Zhang, Bengt Sunden, Weihong Zhang and Gongnan Xie 2015 Constructal Parallel-Flow and Counterflow Microchannel Heat Sinks With Bifurcations, Numerical Heat Transfer, Part A, 68: 1087-1105

[26] Vikas Yadav, Kuldeep Baghel, Ritunesh Kumar and Kadam S T 2016 Numerical investigation of heat transfer in extended surface Microchannels International Journal of Heat and Mass Transfer, 93:612-622

[27] Munson B R, Young D F and Okiishi T H 1998 Fundamental of Fluid Mechanics, 3rd, New York: Wiley, pp. 591-610

[28] Hamid Reza Seyf and Morteza Feizbakhshi 2012 Computational analysis of nanofluid effects on convective heat transfer enhancement of micro-pin-fin heat sink International Journal of Thermal Sciences, 58: 168-179

[29] Shah R K and London A L 1978 Laminar Flow Forced Convection in Ducts, Advances in heat transfer, suppl. 1, New York: Academic press 